\title{
SISTEM PAKAR DIAGNOSA PENYAKIT HEWAN TERNAK KAMBING DENGAN METODE CERTAINTY FACTOR (CF)
}

\author{
Maya Selvia Lauryn', Akhmad Saparudin², Muhamad Ibrohim ${ }^{3}$ \\ ${ }^{1,2,3}$ Jurusan Informatika Fakultas Teknologi Informasi Universitas Serang Raya \\ Jln. Raya Cilegon Serang - Drangong Kota Serang \\ ${ }^{1}$ mysellyn@ gmail.co.id
}

\begin{abstract}
Abstrak - Hewan ternak kambing merupakan hewan ternak banyak memberikan manfaatbagi kehidupan pangan manusia, seperti daging, dan susu. Hewan ternak kambing yang sehat akan menghasilkan daging, dan susu yang berkualitas bagus sehingga meningkatkan harga jual. Penyakit dapat mengganggu pertumbuhan hewan ternak kambing dan jika dibiarkan dapat membunuh hewan ternak kambing. Para peternak sebagian besar masih memiliki pengetahuan yang rendah tentang pengendalian penyakit sedangkan penyakit hewan ternak kambing berkembang subur di daerah yang beriklim tropis seperti Indonesia. Tenaga pakar yang tersedia di daerah pedesaan masih terbatas jumlahnya. Teknologi informasi seperti sistem pakar dapat membantu para peternak dalam melakukan penanganan dini terhadap penyakit yang menyerang hewan ternak kambing. Sistem pakar adalah sistem yang berusaha mengadopsi pengetahuan manusia ke komputer, agar komputer dapat menyelesaikan suatu masalah seperti yang biasa dilakukan oleh para ahli. Penelitian disini menggunakan metode certaity factor dalam memecahkan masalah yang ada pada hewan ternak kambing, dengan kesimpulan bahwa metode certainty factor dapat mengidentifikasikan penyakit hewan ternak kambing dengan hasil 0,28 pada penyakit pink eye.
\end{abstract}

Kata kunci : Certainty factor, hewan ternak kambing, sistem pakar.

\section{PENDAHULUAN}

Kambing merupakan hewan ternak yang banyak memberikan manfaat, seperti daging, susu, dan kulit. Kambing yang sehat akan menghasilkan daging, susu, dan kulit yang berkualitas bagus. Populasi kambing setiap tahunnya mengalami peningkatan dari tahun 2009 sampai 2013 sebesar $4,26 \%$ bila dibandingkan target yang telah ditetapkan(Sumber:www.pertanian.go.id/dinakkeswan_jateng/ files/STATISTIK_NA K2014_FINAL.pdf data dinas peternakan persentase peternakan kambing). Hal ini dikarenakan situasi dan kondisi lingkungan cukup mendukung dan wabah penyakit menular yang sering terjadi sangat rendah kasusnya.Disamping itu peluang usaha untuk ternak kambing juga terbuka luas khususnya untuk konsumsi untuk rumah makan maupun keluarga, sehingga banyak peternak yang mulai membudidayakannya. Peternak kambing di CV. Jaya Laksana usaha pokoknya adalah memelihara ternak kambing. Perusahaan CV. Jaya Laksana ini telah berdiri selama 5 tahun dengan jumlah hewan ternak kambing mencapai 50 ekor. Berdasarkan hasil dari sensus lapangan ternyata peternak sering mengalami kendala penyakit pada hewan ternak kambing yang itu bisa menurunkan harga jual kambing sampai kematian. Hewan ternak kambing yang terkena penyakit hanya sedikit awalnya tapi lama kelamaan banyak. yang terkena penyakit tersebut contoh penyakit cabies,pink eye, cacingan, perut kembung dan diare. Penyakit dapat mengganggu pertumbuhan kambing dan jika dibiarkan dapat membunuh kambing. Para peternak sebagian besar masih memiliki pengetahuan yang rendah tentang pengendalian penyakit sedangkan agen penyakit kambing berkembang subur di daerah yang beriklim tropis seperti Indonesia . Tenaga pakar yang tersedia di daerah pedesaan masih terbatas jumlahnya. Adapun jenis penyakit pada ternak kambing yaitu kembung, cacingan, diare, scabies, orf, pink eyes, masitis, keracunan, kutu, dan penyakit kuku. Salah satu faktor yang mengakibatkan ternak kambing mudah terserang penyakit adalah stres, stres dikarenakan kepadatan jumlah populasi ternak yang ditempatkan dalam satu kandang, kandang kotor, ataupun kualitas pakan yang kurang bagus. Teknologi informasi seperti sistem pakar dapat membantu para peternak dalam melakukan penanganan dini terhadap penyakit yang menyerang kambing. Sistem pakar adalah aplikasi berbasis komputer yang digunakan untuk menyelesaikan masalah sebagaimana yang dipikirkan oleh pakar. Pakar yang dimaksud disini adalah orang yang mempunyai keahlian khusus yang dapat menyelesaikan masalah yang tidak dapat diselesaikan oleh orang awam. Pada dasarnya sistem pakar diterapkan untuk mendukung aktivitas pemecahan masalah. 
Selain itu sistem pakar juga dapat berfungsi sebagai asisten yang pandai dari seorang pakar.Beberapa penelitian telah menerapkan metode Certainty Factor dalam sistem pakar untuk diagnosis penyakit seperti sistem pakar untuk mendiagnosis penyakit menular pada kambing. Pada penelitian ini system pakar dapat mengetahui besar tingkat kepercayaan penyakit yang didiagnosis dengan menggunakan rumus faktor kepastiaan. Dalam hal ini dokter ahli hewan, telah mendefinisikan secara jelas nilai Certainty Factor setiap gejala penyakit terhadap kemungkinan terjadinya penyakit kambing Tujuan penelitian ini adalah membuat aplikasi sistem pakar untuk diagnosis penyakit kambing berbasis visual basic 6.0 menggunakan metode Certainty Factor.

\section{METODOLOGI PENELITIAN}

Metodologi yang digunakan untuk membangun sistem pakar adalah metode analisis perancangan yaitu suatu metode yang bertujuan untuk mendapatkan gambaran yang jelas tentang hal-hal yang diperlukan, melalui tahapan sebagai berikut :

\subsection{Teknik Pengumpulan Data}

a. Studi Literatur.

Pengumpulan data dengan cara mengumpulkan literatur, jurnal, paper dan bacaan-bacaan yang akan di bahas dengan bersumber buku-buku yang ada kaitannya dengan judul penelitian untuk membantu menyelesaikan pembangunan dalam sistem ini.

b. Observasi.

Teknik pengumpulan data dengan mengadakan penelitian danpeninjauan langsung terhadap permasalahan yang diambil melalui komunikasi langsung dengan bagian SDM \& ADM (Sumber Daya Manusia \& Administrasi) terkait yang mengetahui seluk beluk tentang data penyakit hewan kambing.

c. Interview.

Teknik pengumpulan data dengan mengadakan tanya jawab secara langsung yang ada kaitannya dengan topik yang diambil dari Tahap pembuatan perangkat lunak.

\subsection{Perancangan Sistem}

Pada tahap ini yaitu tahap pendefinisian dari kebutuhan fungsional, persiapan untuk rancang bangun implementasi, dan menggambarkan bagaimana suatu program dibangun dengan merancang tampilan input dan tampilan output program.

\subsection{Pembuatan Program}

Pada tahap ini yaitu tahap melakukan penulisan program terhadap desain yang sudah dirancang dan menentukan bahasa pemrograman yang digunakan.

\subsection{Test Program}

Pada tahapan ini dilakukan pengujian untuk mengetahui apakah program aplikasi sesuai dengan yang diharapkan. 2.5 Implementasi
Pada tahap ini yaitu mengimplementasikan atau menerapkan hasil jadi dari sistem yang dibuat.

\subsection{Objek Penelitian}

Penelitan ini dilakukan pada CV. Jaya Laksana.

\section{HASIL DAN PEMBAHASAN}

\subsection{Perancangan Sistem Pakar}

\subsubsection{Tabel Diagnosa}

Tabel diagnosa adalah suatu tabel yang berisikan proses pemeriksaan terhadap suatu tabel dalam menemukan faktor penyebab atau yang menyebabkan masalah yang terdiri dari 23 penyakit dan 25 gejala yang dialami penyakit hewan ternak kambing.

Tabel 3.1 Tabel Diagnosa

\begin{tabular}{|c|c|c|}
\hline No & Penyakit & Gejala \\
\hline P001 & Pink Eye & $\begin{array}{l}\text { Mata kambing berair, bengkak pada } \\
\text { kelopak mata, kambing susah buang } \\
\text { kotoran, kambing terlihat lesu. }\end{array}$ \\
\hline P002 & Cacingan & $\begin{array}{l}\text { Kambing susah buang kotoran, kambing } \\
\text { terlihat lesu, perut kambing terlihat besar, } \\
\text { kambing sulit bernapas. }\end{array}$ \\
\hline P003 & Diare & $\begin{array}{l}\text { Kambing terlihat lesu, perut kambing } \\
\text { terlihat mermbesar, feses lembek sampai } \\
\text { cair. }\end{array}$ \\
\hline P004 & $\begin{array}{l}\text { Myasis } \\
\text { (Belatungan } \\
\text { ) }\end{array}$ & $\begin{array}{l}\text { Bengkak pada kelopak mata, ada yang } \\
\text { bergerak-gerak pada bagian yang terluka, } \\
\text { kulit mengelupas. }\end{array}$ \\
\hline P005 & Kembung & $\begin{array}{l}\text { Perut kabing terlihat besar, diam tidak } \\
\text { mau makan, mencrer berak, tidak mampu } \\
\text { berdiri }\end{array}$ \\
\hline P006 & Acidosis & $\begin{array}{l}\text { Mata kambing berair, kerusakan pada } \\
\text { kulit seperti mengelupas, sering } \\
\text { menggesakkan badan. }\end{array}$ \\
\hline P007 & Scabies & $\begin{array}{l}\text { Bulu mulai rontok, terjadi peradangan } \\
\text { basah, kulit menjadi tebal. }\end{array}$ \\
\hline P008 & Orf & $\begin{array}{l}\text { Perut kambing terlihat membesar, terjadi } \\
\text { peradangan basah, kulit menajdi tebal, } \\
\text { warna air susu kemerahan. }\end{array}$ \\
\hline P009 & Pneumonia & $\begin{array}{l}\text { Kambing terlihat lesu, tidak mampu } \\
\text { berdiri, kerusakan pada kulit, bila } \\
\text { disentuh kambing merasakan kesakitan. }\end{array}$ \\
\hline P010 & Mastitis & $\begin{array}{l}\text { Feses lembek sampai cair, kambing } \\
\text { batuk-batuk, demam, warna air susu } \\
\text { kemerahan }\end{array}$ \\
\hline P011 & $\begin{array}{l}\text { Keracunan } \\
\text { Tanaman }\end{array}$ & $\begin{array}{l}\text { Mata kambing terlihat berair, diam tidak } \\
\text { mau makan, sering menggesekkan badan. }\end{array}$ \\
\hline P012 & $\begin{array}{l}\text { Enterotoxo } \\
\text { mia }\end{array}$ & $\begin{array}{l}\text { Radang basah pada kulit, kebiruan } \\
\text { pada selaput lendir, terjadi pendarahan. }\end{array}$ \\
\hline P013 & Antraks & $\begin{array}{l}\text { Kambing sulit bernapas, kerusakan } \\
\text { pada kulit, demam. }\end{array}$ \\
\hline P014 & Surra & $\begin{array}{l}\text { Kambing terlihat lesu, diam tidak } \\
\text { mau makan, demam. }\end{array}$ \\
\hline P015 & $\begin{array}{l}\text { Kelenjar } \\
\text { Susu }\end{array}$ & $\begin{array}{l}\text { Radang basah pada kulit, warna air } \\
\text { susu kemerahan, bila tersentuh kambing } \\
\text { akan kesakitan. }\end{array}$ \\
\hline P016 & Radang & Kulit menjadi tebal, demam, bila \\
\hline
\end{tabular}




\begin{tabular}{|l|l|l|}
\hline & Pusar & tersentuh kambing merasakan kesakitan. \\
\hline P017 & Demam & $\begin{array}{l}\text { Kambing terlihat lesu, diam tidak mau } \\
\text { makan, mencret berat, demam. }\end{array}$ \\
\hline P018 & Demartitis & $\begin{array}{l}\text { Tidak mampu berdiri, bulu rontok, } \\
\text { demam. }\end{array}$ \\
\hline P019 & $\begin{array}{l}\text { Penyakit } \\
\text { Ngorok }\end{array}$ & $\begin{array}{l}\text { Sulit bernapas, demam, kebiruan pada } \\
\text { selaput lendir. }\end{array}$ \\
\hline P020 & $\begin{array}{l}\text { Radang } \\
\text { Limoah }\end{array}$ & $\begin{array}{l}\text { Radang basah, warna air susu kemerahan, } \\
\text { terjadi pendarahan. }\end{array}$ \\
\hline P021 & Cacar Mulut & $\begin{array}{l}\text { Diam tidak mau makan, sering } \\
\text { menggesekkan badan, demam. }\end{array}$ \\
\hline P022 & $\begin{array}{l}\text { Maligna } \\
\text { Penyakit } \\
\text { Ingusan }\end{array}$ & $\begin{array}{l}\text { Mata Kambing berair, sulit bernapas, } \\
\text { kulit terkelupas. }\end{array}$ \\
\hline P023 & Kuku Busuk & $\begin{array}{l}\text { Terjadi pendarahan, Celah kuku dan tumit } \\
\text { terlihat membengkak, keluaran cairan } \\
\text { kuning dan berbau busuk pada bagian } \\
\text { kuku. }\end{array}$ \\
\hline
\end{tabular}

\subsection{Tabel Matriks}

Tabel matriks adalah Salah satu tabel penghubung antara data gejala dan penyakit yang tertera pada tabel diagnosa yang sangat membantu dalam mengorganisasi pengetahuan, terdiri dari baris (prosedur) dan kolom (sebab) yang menunjukkan Gejala serta penyakit yang terkait satu sama lain.

Hasil penelitian hendaknya dituliskan secara jelas dan padat. Diskusi hendaknya menguraikan arti pentingnya hasil penelitian, bukan mengulanginya. Hindari penggunaan sitasi dan diskusi yang berlebihan tentang literatur yang telah dipublikasikan.

Tabel 3.2 Tabel Matriks



Tabel penyakit disini merupakan pengelompokan data hasil dari tabel matriks yang dirubah menjadi pengkodean dalam pohon keputusan.

Tabel 3.3 Tabel Penyakit

\begin{tabular}{|l|l|l|}
\hline No. & Kode Penyakit & Nama Penyakit \\
\hline 1. & P001 & Pink Eye \\
\hline 2. & P002 & Cacingan \\
\hline 3. & P003 & Diare \\
\hline 4. & P004 & Myasis (belatungan) \\
\hline 5. & P005 & Kembung \\
\hline 6. & P006 & Acidosis \\
\hline 7. & P007 & Sacbies \\
\hline 8. & P008 & Orf \\
\hline 9. & P009 & Penumonia \\
\hline 10. & P010 & Mastitis \\
\hline 11 & P011 & Keracunan Tanaman \\
\hline 12 & P012 & Enterotoxemia \\
\hline 13 & P013 & Antraxs \\
\hline 14 & P014 & Surra \\
\hline 15 & P015 & Kelenjar Susu \\
\hline 16 & P016 & Radang Pusar \\
\hline 17 & P017 & Demam \\
\hline 18 & P018 & Demartitis \\
\hline 19 & P019 & Penyakit Ngorok \\
\hline 20 & P020 & Radang Limoah \\
\hline 21 & P021 & Cacar Mulut \\
\hline 22 & P022 & Maligna (Penyakit Ingusan) \\
\hline 23 & P023 & Kuku Busuk \\
\hline & & \\
\hline
\end{tabular}

\subsection{Pohon Keputusan}

Pohon keputusan merupakan suatu rancangan yang digunakan untuk membangun sistem sebuah sistem pakar. Di dalam diagram pohon keputusan akan dicari solusi akhir dari setiap penelusuran. Diagram pohon keputusan akan mempermudah untuk menyusun basis pengetahuan dan aturan dari setiap penelusuran diagnosis penyakit hewan ternak kambing.



Gambar 3.1 Pohon Keputusan

\subsection{Tabel Aturan (Rule)}

\subsection{Tabel Penyakit}


Tabel aturan/rule adalah suatu pengetahuan untuk mengetahui jalannya gejala suatu penyakit yang telah dijabarkan dalam pohon keputusan untuk menjadi sebuah kaidah aturan dan untuk mempermudah dalam membuat suatu program.

Tabel 3.4 Aturan/Rule

\begin{tabular}{|c|c|}
\hline Rule & Kaidah Aturan \\
\hline Rule 1 & $\begin{array}{l}\text { IF G001 } \\
\text { AND IF G002 } \\
\text { AND IF G003 } \\
\text { AND IF G004 } \\
\text { THEN P001 }\end{array}$ \\
\hline Rule 2 & $\begin{array}{l}\text { IF G003 } \\
\text { AND IF G004 } \\
\text { AND IF G005 } \\
\text { AND IF G008 } \\
\text { THEN P002 } \\
\end{array}$ \\
\hline Rule 3 & $\begin{array}{l}\text { IF G004 } \\
\text { AND IF G005 } \\
\text { AND IF G006 } \\
\text { THEN P003 }\end{array}$ \\
\hline Rule 4 & $\begin{array}{l}\text { IF G002 } \\
\text { AND IF G007 } \\
\text { AND IF G022 } \\
\text { THEN P004 }\end{array}$ \\
\hline Rule 5 & $\begin{array}{l}\text { IF G005 } \\
\text { AND IF G009 } \\
\text { AND IF G010 } \\
\text { AND IF G011 } \\
\text { THEN P005 }\end{array}$ \\
\hline Rule 6 & $\begin{array}{l}\text { IF G001 } \\
\text { AND IF G012 } \\
\text { AND IF G013 } \\
\text { THEN P006 }\end{array}$ \\
\hline Rule 7 & $\begin{array}{l}\text { IF G014 } \\
\text { AND IF G015 } \\
\text { AND IF G016 } \\
\text { THEN P007 }\end{array}$ \\
\hline Rule 8 & $\begin{array}{l}\text { IF G005 } \\
\text { AND IF G015 } \\
\text { AND IF G016 } \\
\text { AND IF G019 } \\
\text { THEN P008 }\end{array}$ \\
\hline Rule 9 & $\begin{array}{l}\text { IF G004 } \\
\text { AND IF G011 } \\
\text { AND IF G012 } \\
\text { AND IF G020 } \\
\text { THEN P009 }\end{array}$ \\
\hline Rule 10 & $\begin{array}{l}\text { IF G006 } \\
\text { AND IF G017 } \\
\text { AND IF G018 } \\
\text { AND IF G019 } \\
\text { THEN P010 }\end{array}$ \\
\hline Rule 11 & $\begin{array}{l}\text { IF G001 } \\
\text { AND IF G009 } \\
\text { AND IF G013 } \\
\text { THEN P011 }\end{array}$ \\
\hline Rule 12 & IF G015 \\
\hline
\end{tabular}

\begin{tabular}{|c|c|}
\hline & $\begin{array}{l}\text { AND IF G021 } \\
\text { AND IF G023 } \\
\text { THEN P012 }\end{array}$ \\
\hline Rule 13 & $\begin{array}{l}\text { IF G008 } \\
\text { AND IF G012 } \\
\text { AND IF G018 } \\
\text { THEN P013 }\end{array}$ \\
\hline Rule 14 & $\begin{array}{l}\text { IF G004 } \\
\text { AND IF G009 } \\
\text { AND IF G018 } \\
\text { THEN P014 }\end{array}$ \\
\hline Rule 15 & $\begin{array}{l}\text { IF G015 } \\
\text { AND IF G019 } \\
\text { AND IF G020 } \\
\text { THEN P015 }\end{array}$ \\
\hline Rule 16 & $\begin{array}{l}\text { IF G016 } \\
\text { AND IF G018 } \\
\text { AND IF G020 } \\
\text { THEN P016 }\end{array}$ \\
\hline Rule 17 & $\begin{array}{l}\text { IF G004 } \\
\text { AND IF G009 } \\
\text { AND IF G010 } \\
\text { AND IF G018 } \\
\text { THEN P017 }\end{array}$ \\
\hline Rule 18 & $\begin{array}{l}\text { IF G011 } \\
\text { AND IF G014 } \\
\text { AND IF G018 } \\
\text { THEN P018 }\end{array}$ \\
\hline Rule 19 & $\begin{array}{l}\text { IF G008 } \\
\text { AND IF G018 } \\
\text { AND IF G021 } \\
\text { THEN P019 }\end{array}$ \\
\hline Rule 20 & $\begin{array}{l}\text { IF G015 } \\
\text { AND IF G019 } \\
\text { AND IF G023 } \\
\text { THEN P020 }\end{array}$ \\
\hline Rule 21 & $\begin{array}{l}\text { IF G009 } \\
\text { AND IF G013 } \\
\text { AND IF G018 } \\
\text { THEN P021 }\end{array}$ \\
\hline Rule 22 & $\begin{array}{l}\text { IF G001 } \\
\text { AND IF G008 } \\
\text { AND IF G022 } \\
\text { THEN P022 }\end{array}$ \\
\hline Rule 23 & $\begin{array}{l}\text { IF G023 } \\
\text { AND IF G24 } \\
\text { AND IF G025 }\end{array}$ \\
\hline
\end{tabular}

\subsection{Tabel CF (Certainty Factor)}

Tabel CF merupakan penilaian persentase penyakit yang dipastikan oleh seorang pakar yang ada pada tanaman cabai merah. Tabel tersebut sebagai berikut :

Tabel 3.6 Persentase Penyakit

\begin{tabular}{|l|l|l|l|l|}
\hline Rule & Kaidah Aturan & Mb & Md & CF \\
\hline \multirow{4}{*}{ Rule 1 } & IF G001 & & & \\
& $\begin{array}{l}\text { AND IF G002 } \\
\text { AND IF G003 } \\
\text { AND IF G004 }\end{array}$ & 0.9 & 0.2 & 0.7 \\
\hline
\end{tabular}




\begin{tabular}{|c|c|c|c|c|}
\hline & THEN P001 & & & \\
\hline Rule 2 & $\begin{array}{l}\text { IF G003 } \\
\text { AND IF G004 } \\
\text { AND IF G005 } \\
\text { AND IF G008 } \\
\text { THEN P002 }\end{array}$ & 0.8 & 0.1 & 0.7 \\
\hline Rule 3 & $\begin{array}{l}\text { IF G004 } \\
\text { AND IF G005 } \\
\text { AND IF G006 } \\
\text { THEN P003 }\end{array}$ & 0.8 & 0.2 & 0.6 \\
\hline Rule 4 & $\begin{array}{l}\text { IF G002 } \\
\text { AND IF G007 } \\
\text { AND IF G022 } \\
\text { THEN P004 }\end{array}$ & 0.8 & 0.05 & 0.75 \\
\hline Rule 5 & $\begin{array}{l}\text { IF G005 } \\
\text { AND IF G009 } \\
\text { AND IF G010 } \\
\text { AND IF G011 } \\
\text { THEN P005 }\end{array}$ & 0.7 & 0.05 & 0.65 \\
\hline Rule 6 & $\begin{array}{l}\text { IF G001 } \\
\text { AND IF G012 } \\
\text { AND IF G013 } \\
\text { THEN P006 }\end{array}$ & 0.7 & 0.1 & 0.6 \\
\hline Rule 7 & $\begin{array}{l}\text { IF G014 } \\
\text { AND IF G015 } \\
\text { AND IF G016 } \\
\text { THEN P007 }\end{array}$ & 0.8 & 0.2 & 0.6 \\
\hline Rule 8 & $\begin{array}{l}\text { IF G005 } \\
\text { AND IF G015 } \\
\text { AND IF G016 } \\
\text { AND IF G019 } \\
\text { THEN P008 }\end{array}$ & 0.7 & 0.1 & 0.6 \\
\hline Rule 9 & $\begin{array}{l}\text { IF G004 } \\
\text { AND IF G011 } \\
\text { AND IF G012 } \\
\text { AND IF G020 } \\
\text { THEN P009 }\end{array}$ & 0.9 & 0.1 & 0.8 \\
\hline Rule 10 & $\begin{array}{l}\text { IF G006 } \\
\text { AND IF G017 } \\
\text { AND IF G018 } \\
\text { AND IF G019 } \\
\text { THEN P010 }\end{array}$ & 0.8 & 0.1 & 0.7 \\
\hline Rule 11 & $\begin{array}{l}\text { IF G001 } \\
\text { AND IF G009 } \\
\text { AND IF G013 } \\
\text { THEN P011 }\end{array}$ & 0.8 & 0.2 & 0.6 \\
\hline Rule 12 & $\begin{array}{l}\text { IF G015 } \\
\text { AND IF G021 } \\
\text { AND IF G023 } \\
\text { THEN P012 }\end{array}$ & 0.9 & 0.2 & 0.7 \\
\hline Rule 13 & $\begin{array}{l}\text { IF G008 } \\
\text { AND IF G012 } \\
\text { AND IF G018 } \\
\text { THEN P013 }\end{array}$ & 0.8 & 0.1 & 0.7 \\
\hline Rule 14 & $\begin{array}{l}\text { IF G004 } \\
\text { AND IF G009 } \\
\text { AND IF G018 } \\
\text { THEN P014 }\end{array}$ & 0.8 & 0.05 & 0.75 \\
\hline Rule 15 & $\begin{array}{l}\text { IF G015 } \\
\text { AND IF G019 } \\
\text { AND IF G020 }\end{array}$ & 0.7 & 0.1 & 0.6 \\
\hline
\end{tabular}

\begin{tabular}{|c|c|c|c|c|}
\hline & THEN P015 & & & \\
\hline Rule 16 & $\begin{array}{l}\text { IF G016 } \\
\text { AND IF G018 } \\
\text { AND IF G020 } \\
\text { THEN P016 }\end{array}$ & 0.9 & 0.2 & 0.7 \\
\hline Rule 17 & $\begin{array}{l}\text { IF G004 } \\
\text { AND IF G009 } \\
\text { AND IF G010 } \\
\text { AND IF G018 } \\
\text { THEN P017 }\end{array}$ & 0.8 & 0.1 & 0.7 \\
\hline Rule 18 & $\begin{array}{l}\text { IF G011 } \\
\text { AND IF G014 } \\
\text { AND IF G018 } \\
\text { THEN P018 }\end{array}$ & 0.8 & 0.1 & 0.7 \\
\hline Rule 19 & $\begin{array}{l}\text { IF G008 } \\
\text { AND IF G018 } \\
\text { AND IF G021 } \\
\text { THEN P019 }\end{array}$ & 0.9 & 0.1 & 0.8 \\
\hline Rule 20 & $\begin{array}{l}\text { IF G015 } \\
\text { AND IF G019 } \\
\text { AND IF G023 } \\
\text { THEN P020 }\end{array}$ & 0.9 & 0.2 & 0.7 \\
\hline Rule 21 & $\begin{array}{l}\text { IF G009 } \\
\text { AND IF G013 } \\
\text { AND IF G018 } \\
\text { THEN P021 }\end{array}$ & 0.8 & 0.05 & 0.75 \\
\hline Rule 22 & $\begin{array}{l}\text { IF G001 } \\
\text { AND IF G008 } \\
\text { AND IF G022 } \\
\text { THEN P022 }\end{array}$ & 0.9 & 0.2 & 0.7 \\
\hline Rule 23 & $\begin{array}{l}\text { IF G023 } \\
\text { AND IF G24 } \\
\text { AND IF G025 } \\
\text { THEN P023 }\end{array}$ & 0.9 & 0.1 & 0.8 \\
\hline
\end{tabular}

\subsection{Perancangan Sistem Secara Umum}

\section{A. Use Case Diagram}



Gambar 3.2 Use case diagram 
IV Kesimpulan

Dari hasil pengujian terhadap identifikasi maslah Aplikasi Sistem Pakar Diagnosa penyakit kambing yang dibangun, kesimpulannya adalah :

1. Dengan adanya sistem pakar diagnosa penyakit pada hewan ternakkambing dengan menggunakan metode Certainty Factor, peternak kambing dapat menyelesaikan masalah yaitu bisa menampilkan hasil diagnosa dengan cepat dan tepat berdasarkan gejala-gejala yangdimasukan oleh user.

2. Dengan metode certainty factor Untuk membuat hasil diagnosa menjadisangat valid, maka data gejala yang dimasukan oleh seorang administrator/ pakar kedalam suatu data penyakit, harus lengkap artinya gejala-gejala yang bisa mengarah ke suatu penyakit tersebut harus dimasukan secara lengkap, karena kesimpulan hasil diagnosa (persentase) yang ditampilkan dihitung secara otomatis oleh sistem. Sehingga dari persentase itulah, user bisa mengetahui penyakit apa yang diderita dan kemungkinan mendapatkan penyakit yang lain.

\section{REFERENSI}

[1] Abdul, S. (2012). Metode Certainty Factor. [Online]. Tersedia:https://asanisembiring.wordpress.com/2012/ 03/19/metode-certainty-factor/ [23 April 2015].

[2] Ardi, G. (2014). Cara Mengobati Kambing. [Online]. Tersedia:

http://carapraktisall.blogspot.co.id/2014/03/carameng obatikambing.html [23 April 2015]

[3] Ardisa, P. (2011). Sistem Pakar Diagnosa Penyakit Sapi Ternak Berbasis Web dengan Metode Certainty Factor dan Forward Chaining. Tersedia: http://library.gunadarma.ac.id//repository/view/3770 259

[4] Ramadhan, A. (2005). SQL Server 2000 dan Visual BASIC 6. Bogor: PT. Elex Media Komputindo Gramedia, Jakarta

[5] Fajrin Sidik. (2014). Obat-Obat Herbal Untuk Mengobati Penyakit Kambing. [Online]. Tersedia: http://www.ternakpertama.com/2014/09/Obatherbaluntuk-mengobati-penyakit-pada-kambing.html. [25 April 2015].

[6] Fisti, D. (2013). Analisa Perbandingan Metode Naive Bayesian Dan Certainty Factor Pada Sistem Pakar Dalam Mendiagnosa Penyakit Radang Genitalia. Vol. 9 [Online].

Tersedia: http://jurnal.umrah.ac.id/?p=2297 [25 April 2015]

[7] Lesmardine. (2013). Metode Certainty Factor. [Online]. Tersedia: https://lesmardin1988.wordpress.com/2013/10/16/me tode-certainty-factorcf/. [25 April 2015].
[8] Luther, A. (2012). Sistem Pakar Pendiagnosa Penyakit Anak Menggunakan Certainty Factor (Cf). [Online]. Vol. 12. No. (2).

[9] Rohajawati, Supriyati. (2010). Sistem Pakar: Diagnosis Penyakit Unggas Dengan Metode Certainty Factor. Vol. 4. No.(1). 41-46.

[10] Pratiwi, Pebdrianty. (2014). Sistem Pakar Untuk Diagnosa Penyakit Pada Hewan Ternak Kambing Berbasis Mobile. Other thesis, UPN "Veteran" Yogyakarta. http://eprints.upnyk.ac.id/5284/.

[11]Reski Mai Candra, Weni Rahim. (2014). Sistem Pakar Diagnosa Bibit Unggul Sapi Dan Kambing Dengan Metode Certainty Factor. [Online]. Vol. 3. No. (1). 17-22.

[12] Sutojo, T. dkk. (2011). Kecerdasan Buatan. Semarang: ANDI Yogyakarta. 